\title{
BER estimation for all-optical regenerators influenced by pattern effects
}

\author{
Bischoff, Svend; Lading, B.; Mørk, Jesper
}

Published in:

I E E E Photonics Technology Letters

Link to article, DOI:

10.1109/68.974152

Publication date:

2002

Document Version

Publisher's PDF, also known as Version of record

Link back to DTU Orbit

Citation (APA):

Bischoff, S., Lading, B., \& Mørk, J. (2002). BER estimation for all-optical regenerators influenced by pattern effects. I E E E Photonics Technology Letters, 14(1), 33-35. https://doi.org/10.1109/68.974152

\section{General rights}

Copyright and moral rights for the publications made accessible in the public portal are retained by the authors and/or other copyright owners and it is a condition of accessing publications that users recognise and abide by the legal requirements associated with these rights.

- Users may download and print one copy of any publication from the public portal for the purpose of private study or research.

- You may not further distribute the material or use it for any profit-making activity or commercial gain

- You may freely distribute the URL identifying the publication in the public portal

If you believe that this document breaches copyright please contact us providing details, and we will remove access to the work immediately and investigate your claim 


\title{
BER Estimation for All-Optical Regenerators Influenced by Pattern Effects
}

\author{
Svend Bischoff, Brian Lading, and Jesper Mørk
}

\begin{abstract}
An efficient method is presented for the estimation of the bit-error rate (BER) of a system employing all-optical regenerators influenced by pattern effects. We theoretically study noise accumulation and noise redistribution in long distance transmission systems employing a delayed interference signal wavelength converter for all-optical regeneration. The BER is studied for return-to-zero signals at bit rates of $2.5 \mathrm{~Gb} / \mathrm{s}$ (no patterning) up to $40 \mathrm{~Gb} / \mathrm{s}$ (strong patterning). The calculation of the BER is based on pattern dependent transfer functions, which may be obtained numerically or measured.
\end{abstract}

Index Terms-All-optical regeneration, optical communications, semiconductor optical amplifiers.

\section{INTRODUCTION}

$\mathbf{I}$ $\mathrm{N}$ ALL-OPTICAL high-capacity networks, noise accumulation due to optical amplifiers, wavelength converters, and switching require signal restoration procedures. Promising components for all-optical signal regeneration include interferometric wavelength converters, in which semiconductor optical amplifiers (SOAs) are used as optical phase shifters [1]. The noise redistribution capabilities of these wavelength converters, which have been demonstrated experimentally [2], [3], can be described through the transfer function, which should exhibit a nonlinear thresholding characteristic. With increasing data rates of 40 and $160 \mathrm{~Gb} / \mathrm{s}$, the devices are influenced by pattern effects, which will decrease the regeneration performance. In this letter, an efficient theoretical tool is presented to estimate the BER penalty due to pattern effects. The technique is based on the use of pattern dependent transfer functions, which may be obtained experimentally or theoretically. As a specific example, we present calculations for the case of an SOA-based interferometer operating at bit rates of $2.5-40 \mathrm{~Gb} / \mathrm{s}$.

\section{THE THEORETICAL APPROACH}

The model used to estimate the regeneration performance is based on a scheme suggested in [4] for the case of static nonlinear transfer functions. Here, we extend the method suggested in [4] to the dynamical case by introducing pattern dependent nonlinear transfer functions. The probability density functions (PDFs) for both marks and spaces are assumed known initially. In our case, we assume that signal independent Gaussian noise is added after each transmission link due to signal spontaneous beat noise from inline erbium-doped fiber amplifiers

Manuscript received July 13, 2001; revised October 1, 2001. This work was supported by the Danish research council under the SCOOP project.

The authors are with the Research Center COM, Technical University of Denmark, DK-2800 Kgs. Lyngby, Denmark (e-mail: sb@com.dtu.dk).

Publisher Item Identifier S 1041-1135(02)00117-9.

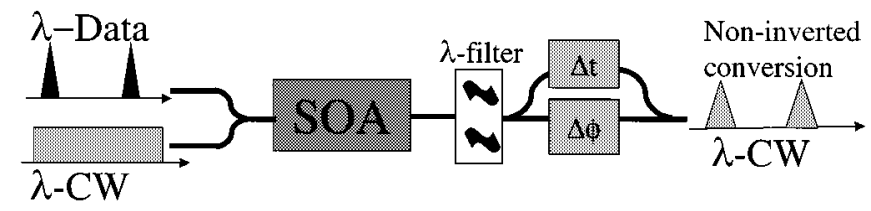

Fig. 1. Schematic of the DISC.

(EDFAs). Amplified spontaneous emission noise from the interferometric wavelength converter is assumed negligible. In the case of SOA-based interferometers, this is justified since the SOA is strongly saturated by the high power levels of both the data and continuous-wave (CW) signals. The effect of timing jitter is neglected in our treatment and the model thus only considers reshaping and reamplification of the signal by the regenerator (2R-regeneration). The bit-error rate (BER) penalty resulting from timing jitter is beyond the scope of this letter, since this requires a detailed investigation of the combined effect of amplitude and timing jitter within SOA-based 2R regenerators.

The redistribution of the PDF for the mark and space levels by the interferometer is governed by the nonlinear transfer function of the regenerator. In the numerical implementation, the PDFs are discretized, and the corresponding probabilities are represented by vectors. The transformation properties of the regenerator is represented by a matrix, in which the noise is included. In the dynamical case considered here, the nonlinear transfer function depends on the prehistory of the signal, as explained below. A sequence of links is then analyzed by simple matrix multiplication (see [4] for details).

Here, we have chosen to use the calculated transfer function of an delayed interference signal wavelength converter (DISC) [5], [6]. A schematic of the DISC is shown in Fig. 1. The working principle of the DISC interferometer is as follows. The return-to-zero (RZ) data signal is combined with a $\mathrm{CW}$ signal, at a wavelength different from the data signal, and injected into an SOA. The modulated data signal will modulate the gain and refractive index of the SOA, and thus, both the phase and the amplitude of the $\mathrm{CW}$ signal are modified. The data signal is removed after the SOA by a filter and the CW signal passes an interferometer, where the $\mathrm{CW}$ signal in one arm of the interferometer is delayed with respect to the other arm by a fixed time $\Delta t$. The data signal is recovered due to the interference of the $\mathrm{CW}$ signals from the two interferometer arms. The phase shifter shown in the lower arm can be adjusted for optimum operation conditions. Similar results are expected for other types of regenerators based on SOAs, since the dynamics of the SOAs determine the magnitude of the pattern effects.

A large signal model accounting for the dynamics of the DISC is used to calculate the pattern dependent transfer 


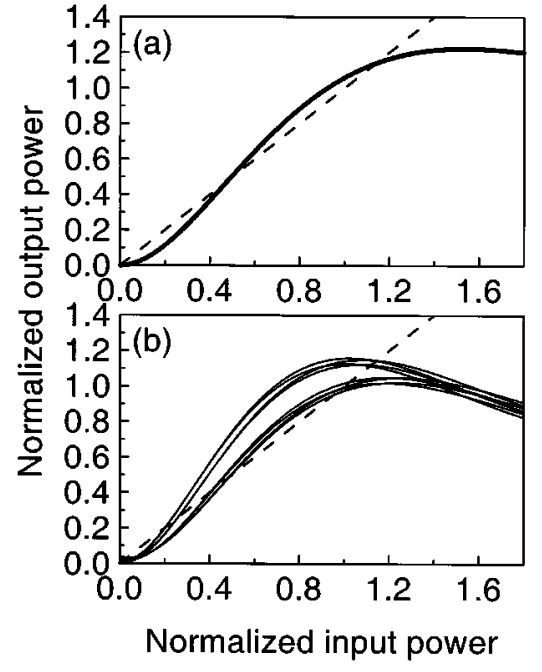

Fig. 2. Transfer function characteristics of DISC at (a) 2.5 and (b) $40 \mathrm{~Gb} / \mathrm{s}$. Strong patterning effects are observed at $40 \mathrm{~Gb} / \mathrm{s}$. The linear transfer function is shown as a reference (dashed line).

functions. A description of the large signal model of the SOA can be found in [7]. An example of calculated transfer function characteristics at 2.5 and $40 \mathrm{~Gb} / \mathrm{s}$ is shown in Fig. 2 . The transfer functions are calculated by first optimizing the DISC for observing a clear and open optical eye in case of wavelength conversion. The transfer function is then calculated by injecting a sequence of bits, e.g., four bits. The pulse power following this initial short bit sequence is subsequently varied to determine the nonlinear transfer function. This is repeated for all possible combinations of mark and space levels for the initial four bits. In this way, one obtains nonlinear transfer functions (16 different for the case of an initial 4-bit sequence) that are labeled by the initial bit pattern. The initial number of bits is chosen such that no additional change of the transfer function will be observed when increasing the bit-sequence with an additional bit. In general, the length of the initial bit sequence will of course be determined by the memory time of the amplifier, and the number of initial bits will, thus, depend on the bit rate.

The strong patterning effects at $40 \mathrm{~Gb} / \mathrm{s}$ in Fig. 2 arise because the SOA has not been optimized for high-speed operation; better results can be obtained using, e.g., a longer SOA. The aim here is, thus, to study the general influence of patterning effects on the regeneration performance.

\section{Pattern Dependent Regeneration}

Fig. 3 shows the estimated BER as a function of the number of regenerator nodes. The BER of the first span, i.e., transmission fiber, amplifier, and regenerator has been set equal to $10^{-14}$, which is a measure of the noise (loss) of the span [4]. The transfer functions for 10 and $20 \mathrm{~Gb} / \mathrm{s}$ have not been shown, but as seen from Fig. 3, only a very small penalty due to patterning effects is observed at $10 \mathrm{~Gb} / \mathrm{s}$, while we find large BER penalties at 20 and $40 \mathrm{~Gb} / \mathrm{s}$. At a bit rate of $2.5 \mathrm{~Gb} / \mathrm{s}$, patterning effects are negligible, while it is evident that the pattern dependent transfer functions at 20 and $40 \mathrm{~Gb} / \mathrm{s}$ result in significant BER penalties.

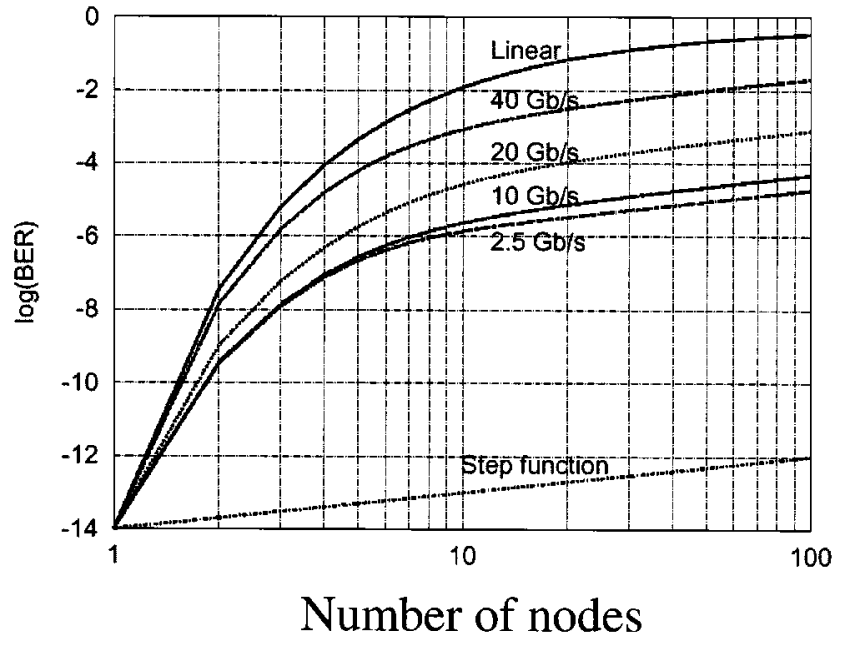

Fig. 3. BER estimates versus number of nodes for bit rates of 2.5, 10, 20, and $40 \mathrm{~Gb} / \mathrm{s}$ when pattern effects are taken into account

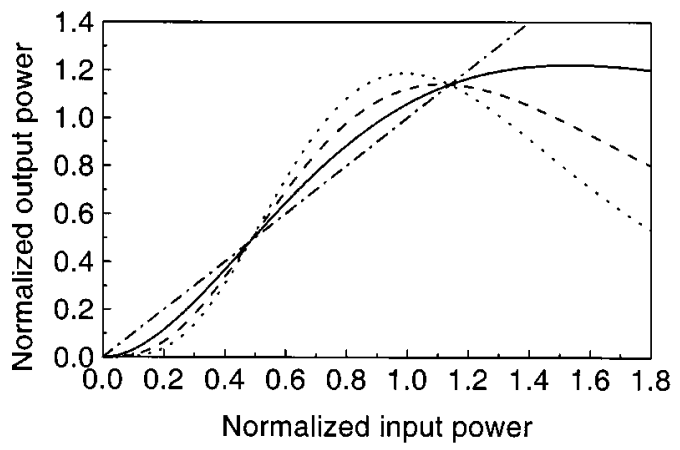

Fig. 4. Transfer functions for the case of 1 (solid), 2 (dashed), and 3 (dotted) cascaded regenerators at each regenerator node. The dashed-dotted line is the linear transfer function, which corresponds to the case of no regeneration.

The upper BER curve marked "linear" corresponds to the case of no regeneration, while the lower curve marked "step function" corresponds to an ideal regenerator with a step-function characteristic. The small improvement of the BER compared to the "linear" BER curve is due to the small nonlinearity of the transfer functions of the DISC interferometer. The nonlinearity of the transfer function can be improved by cascading a finite number of DISCs at each regeneration node. Fig. 4 shows how the nonlinearity (step-like character) of the transfer function increases when cascading 1,2, and 3 regenerators at each node.

The BER estimates when cascading two DISCs at each node are shown in Fig. 5. Clearly, the regeneration properties are strongly improved compared to the case of using just one interferometer at each node (at the price of increased complexity), but the penalty due to pattern effects is almost unchanged.

It should be emphasized, that the BER before and after a regenerator is the same in case of pattern independent nonlinear transfer functions. The noise of the mark and space levels is just redistributed in such a way, that the BER observed after the next EDFA will be reduced compared to the case of no regenerator. However, in the case of pattern dependence, the BER will only be the same in case the nonlinear transfer functions cross each other at the input power threshold level. The input power threshold level corresponds to the power level resulting 


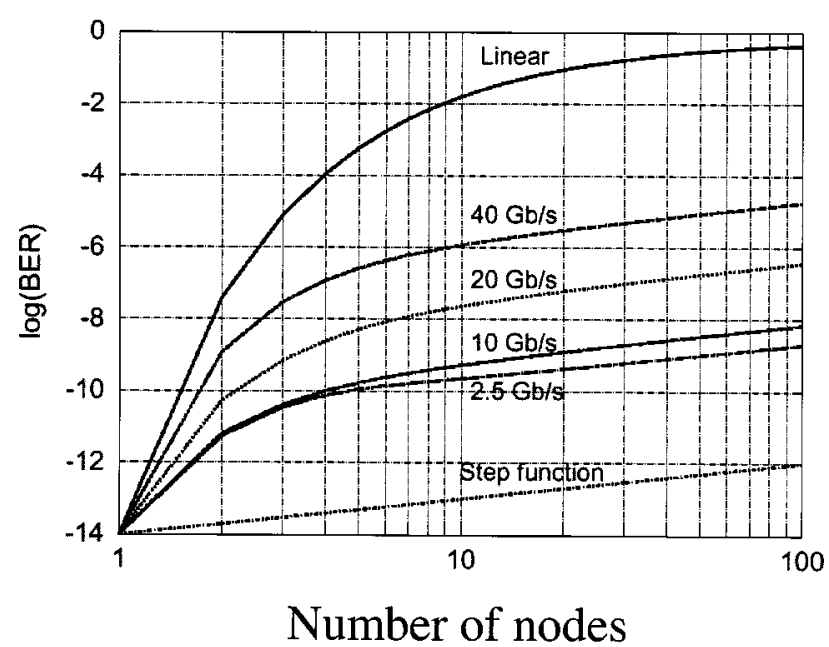

Fig. 5. BER estimates at 2.5, 10, 20, and $40 \mathrm{~Gb} / \mathrm{s}$ when cascading two regenerators at each node.

in minimum BER in front of the regenerator. The BER will, thus, typically increase when passing a regenerator with pattern dependent nonlinear transfer functions.

Despite the penalty caused by the patterning effects at each node, the pattern dependent nonlinear transfer functions will still result in a redistribute of the noise on the mark and space levels, as seen in Figs. 3 and 5. However, the amount of noise added decreased with increasing patterning effects in Figs. 3 and 5 , since the BER after the first regenerator was kept fixed. Signal regeneration compared to the linear case (no regeneration) is, thus, not necessarily observed after the first regenerator in case of pattern dependence, but only after a finite number of regenerator nodes.

\section{CONCLUSION}

A simple method for calculating the trends of BER versus number of nodes in systems with all-optical $2 \mathrm{R}$-regenerators has been presented. Compared to previous results [4], the method takes into account pattern effects by introducing pattern dependent transfer functions, which may be obtained numerically or experimentally. We analyzed the specific case of a DISC-regenerator, and calculated the BER dependence on number of nodes and bit rate, revealing large penalties for bit rates above $10 \mathrm{~Gb} / \mathrm{s}$ in the specific case considered. We also showed how cascading of interferometers at the nodes may significantly improve the performance.

\section{ACKNOWLEDGMENT}

The authors thank B. Tromborg and H. N. Poulsen for fruitful discussions.

\section{REFERENCES}

[1] T. Durhuus, B. Mikkelsen, C. Joergensen, S. L. Danielsen, and K. E. Stubkjaer, "All-optical wavelength conversion by semiconductor optical amplifiers," J. Lightwave Technol., vol. 14, pp. 942-954, June 1996.

[2] H. J. Thiele, A. D. Ellis, and J. D. Philips, "Recirculating loop demonstration of $40 \mathrm{Gbit} / \mathrm{s}$ all-optical 3R regeneration using a semiconductor nonlinear interferometer," Electron. Lett., vol. 35, pp. 230-231, 1999.

[3] O. Leclerc, B. Danny, D. Rouvillian, P. Brindel, E. Desurvire, C. Duchet, A. Shen, F. Devaux, A. Coquelin, M. Goix, S. Bouchoule, L. Fleury, and P. Nouchi, "Simultaneously regenerated $4 \times 40 \mathrm{Gbit} / \mathrm{s}$ dense WDM transmission over $10000 \mathrm{~km}$ using single $40 \mathrm{Ghz}$ InP Mach-Zehnder modulator," Electron. Lett., vol. 36, pp. 1574-1575, 2000.

[4] P. Ohlén and E. Berglind, "Noise accumulation and BER estimates in concatenated nonlinear optoelectronic repeaters," IEEE Photon. Technol. Lett., vol. 9, pp. 1011-1013, July 1997.

[5] Y. Ueno, S. Nakamura, K. Tajima, and S. Kitamura, "3.8-THz wavelength conversion of picosecond pulses using a semiconductor delayed interference signal-wavelength converter (DISC)," IEEE Photon. Technol. Lett., vol. 10, pp. 346-348, Mar. 1998.

[6] J. Leuthold, C. H. Joyner, B. Mikkelsen, G. Raybon, J. L. Pleumeekers, B. I. Miller, K. Dreyer, and C. A. Burrus, " $100 \mathrm{Gbit} / \mathrm{s}$ all-optical wavelength conversion with integrated SOA delayed-interference configuration," Electron. Lett., vol. 36, pp. 1129-1130, 2000.

[7] S. Bischoff, A. Buxens, A. Clausen, H. N. Poulsen, and J. Mørk, "Bi-directional four wave mixing in semiconductor optical amplifiers: Theory and experiment," J. Lightwave Technol., vol. 17, pp. 1617-1625, Sept. 1999. 